\title{
ESTUDIO SOBRE EL USO DEL PRESENTE EN UN SERIAL TELEVISIVO COLOMBIANO ${ }^{1}$
}

\author{
Alba García Rodríguez
}

\begin{abstract}
Present tense is the most widely used tense in the Spanish verbal system. Although this tense normally appears related to present situations, it can show a big variety of meanings depending on the context. In this paper, we analyze the main uses of the present tense in the Colombian soap opera called Sin tetas no hay paraíso, based on the novel written by Gustavo Bolívar. This is a good material to study because of its dynamic and realistic dialogues, so we can know the Spanish spoken in Colombia nowadays. We analyze the different uses of the present tense and the relations with the rest of the elements of the statement (horizontal relationships). It is discovered that there is a great variety of uses and meanings of the present tense also in this Colombian soap opera.

Keywords: present tense; soap opera; Colombian Spanish; spoken Spanish; descriptive analysis.

Resumen: El presente de indicativo es el tiempo más utilizado del sistema verbal español. Aunque normalmente aparece vinculado a situaciones temporalmente relacionadas con el momento de la enunciación, puede adquirir una gran variedad de significados dependiendo del contexto. En este trabajo se analizan los principales usos del presente en la telenovela colombiana Sin tetas no hay paraíso, basada en la novela homónima de Gustavo Bolívar. Se trata de un auténtico «documental lingüístico» que, a través de sus diálogos dinámicos y realistas, ofrece una imagen bastante acertada del español actual hablado en Colombia. Tomando ese corpus de estudio, se analizan las formas del presente teniendo siempre muy en cuenta sus relaciones con el resto de los elementos del enunciado (las llamadas relaciones horizontales o in praesentia saussureanas). Se descubre así el gran uso y diversidad de matices que el presente adquiere también en este serial colombiano: progresividad, certeza, futuridad, mandato, etc.
\end{abstract}

Palabras claves: presente de indicativo; telenovela; español colombiano; español oral; análisis descriptivo.

\section{Introducción}

Dentro del sistema verbal del español, el presente de indicativo constituye, sin duda, uno de los tiempos verbales más utilizados en el día a día. En las distintas variedades dialectales del español, este tiempo verbal presenta muchos matices de significado dependiendo del contexto donde aparezca. A pesar de eso, en la mayoría de los manuales generales sobre el español de América (Kany 1970; Lapesa 1981; Moreno de Alba 1988;

\footnotetext{
1 Esta investigación ha podido ser llevada a cabo, gracias a la financiación aportada por la Beca de Formación del Profesorado Universitario (FPU) concedida por el Ministerio de Educación del Gobierno de España, con la siguiente referencia: AP2010-0271.
} 
Frago y Franco 2001; Aleza y Enguita 2002; Lipski 2007) no se le presta mucha atención al uso de este tiempo verbal, ya que normalmente se les dedican muchas páginas a fenómenos gramaticales más «pintorescos» desde el punto de vista de su mayor alejamiento de la norma estándar del español (como son las construcciones perifrásticas, el empleo del pretérito indefinido y del pretérito compuesto, los usos reflexivos de los verbos, el voseo, etc.), quizás porque se da por supuesto que los usos del presente en las distintas modalidades americanas no difieren sustancialmente de los usos que pueden encontrarse recogidos en cualquier manual de gramática general del español. Sin embargo, dentro de la investigación lingüística es fundamental que no se dé nada por sabido, pues es necesario analizar todas las características lingüísticas que definen nuestra forma de hablar si queremos llegar a un conocimiento en profundidad de nuestro idioma.

Para este trabajo, se han tomado como objeto de estudio las transcripciones ortográficas realizadas sobre la serie colombiana Sin tetas no hay paraíso, basada en la novela homónima de Gustavo Bolívar y realizada por Caracol Televisión. En dicho serial se narra la historia de un grupo de chicas que viven en la ciudad colombiana de Pereira y que se introducen en el peligroso mundo de la prostitución para mejorar sus condiciones de vida. De esa manera, pasan a servir a importantes narcotraficantes que las recompensan con todo tipo de bienes materiales. El título de la serie remite a la historia de la protagonista, Catalina, quien al igual que otras muchas chicas de su ciudad, decide prostituirse para poder financiarse una operación de aumento de pechos. A pesar de los consejos de sus familiares, Catalina se adentra en un ámbito lleno de traiciones y violencia y, cuando comprende que el precio que ha pagado por cumplir su sueño es demasiado alto, ya no hay marcha atrás. A través de este argumento, la serie pretende servir de crítica a la compleja situación que viven algunos países en la actualidad, haciendo especial hincapié en el problema del narcotráfico y de la prostitución.

En lo que respecta a la elección de este material de estudio, hay que destacar el gran interés que suscitan los comúnmente llamados culebrones en muchos países, no solo pertenecientes al dominio hispánico, sino también muy alejados geográfica y culturalmente. Como consecuencia, este tipo de programas constituyen en la actualidad un poderoso medio de difusión de la lengua española por todo el mundo. López Morales (2010) concede gran atención al papel desempeñado por las telenovelas y considera que dentro de la historia de estas producciones pueden distinguirse tres etapas: la primera se caracterizó por la producción nacional, lo que dio lugar a ficciones de un marcado tinte local y con abundancia de localismos; una segunda etapa que supuso el comienzo de la distribución internacional de estas series y las coproducciones con actores de distintas procedencias, lo que a menudo exigía la neutralización de algunos rasgos lingüísticos para favorecer una mejor comprensión; por último, en la tercera etapa tuvo lugar la internalización sin precedentes de estos programas televisivos. En este caso, se podría dar un paso más allá y considerar la serie Sin tetas no hay paraíso dentro de una cuarta etapa de telenovelas, acuñando el término de "serial de cuarta generación», ya que en esta producción televisiva no se pierde de vista la difusión internacional del producto, pero a la vez se intentan recuperar ciertos rasgos lingüísticos y culturales que caracterizan a una determinada comunidad. Además, al tratarse de una serie creada para su difusión televisiva, la neutralización lingüística es menor que la puede aparecer en una película, debido a la premura con que deben grabarse los capítulos. Esto ocasiona que, a menudo, los actores dejen entrever rasgos de su propio idiolecto. 
No obstante, los verdaderos motivos que explican la elección de este material de estudio se corresponden a criterios lingüísticos y, en ese sentido, el serial constituye un auténtico «documental lingüístico» que nos acerca de manera bastante verídica al habla que se utiliza día a día en la ciudad colombiana de Pereira. Por lo general, se presentan diálogos muy espontáneos y vivos; además, esta serie se detiene en las formas de vida de los sectores más populares de la población. Este hecho es muy significativo ya que, muchas veces, las telenovelas reflejan formas de vida de personajes de escala social alta, por lo que la recreación del lenguaje siempre resulta un poco más afectada, impidiendo así un acercamiento más auténtico a la lengua hablada. Sin embargo, el alto poder adquisitivo de algunos de los personajes de la serie (los narcotraficantes) no se corresponde con un alto nivel educativo y cultural, sino que presentan un lenguaje muy coloquial, en ocasiones con un cierto carácter jergal. Por otra parte, su valor documental también se puede aplicar a la crítica sociológica, ya que la serie se acerca a algunos de los problemas más complejos que afectan a la sociedad actual de algunas zonas del país, como la prostitución o el narcotráfico. Por lo general, esta caracterización lingüística y social se lleva a cabo de una manera bastante realista.

En las últimas décadas, los estudios gramaticales han empezado a prestar una mayor atención a la descripción y caracterización de los usos orales del lenguaje, considerados durante mucho tiempo el «patito feo» de la lingüística:

Como la lengua coloquial ha sido juzgada casi siempre desde la óptica de la lengua escrita culta, tradicionalmente se ha hablado de su imprecisión, de su pobreza léxica y de su descuido formal, términos todos ellos peyorativos, con los que, entre otros, se aludía además a lo poco adecuado y recomendable que sería adoptarla como objeto de estudio o como modelo de referencia. Nuestro punto de vista está, sin embargo, cambiando. Ahora consideramos ya que la lengua coloquial puede y debe ser estudiada como específicamente oral, hablada (y no como simple desviación negativa de la estándar). (Vigara 1996: 15)

Pese a la gran riqueza lingüística que presenta este tipo de producciones televisivas además, claro está, de su gran capacidad de influencia en los distintos ámbitos de la vida humana, los estudios en este ámbito siguen siendo bastante escasos, más aún desde la perspectiva del análisis lingüístico. Como señala Cisneros (2009: 9):

La telenovela en Colombia, difunde normas y tendencias culturales, y tiene una enorme influencia en las percepciones y opiniones del público, por lo que se hacen necesarios estudios desde el nivel discursivo que den cuenta de la manera cómo la sociedad adopta el lenguaje de la televisión con toda su carga semántica, conceptual y pedagógica.

López Morales (2010) también destaca la importancia de las telenovelas en su labor de difusión de la lengua española por todo el mundo, debido al éxito que han alcanzado en los últimos años, hasta tal punto que Salvador (apud López Morales 2010: 414) afirma que «los culebrones pueden hacer más por el idioma castellano que, por ejemplo, una reunión de academias». Si pensamos en la gran cantidad de países en los que se ha emitido esta serie (Ecuador, Venezuela, Chile, México, Estados Unidos, entre otros), cosechando además un gran éxito en muchos de ellos, podemos comprobar la gran importancia de este tipo de producciones televisivas como un potente aliado para conocer mejor los rasgos lingüísticos que caracterizan a algunas de las variedades del español en América.

Para el presente trabajo se han utilizado dos de los veintitrés capítulos que conforman la serie con una duración de cuarenta minutos cada uno: se trata de los capítulos tres 
y cinco. El primero de ellos está formado por 5.545 palabras y el segundo por 5.745, por lo que nuestro corpus de estudio consta aproximadamente de 11.290 palabras.

La estructura del trabajo es la siguiente: en primer lugar, se sitúa el lugar donde transcurre la acción del serial analizado dentro de las divisiones dialectales del español colombiano y se explican de manera breve algunas de las principales características lingüísticas que definen cada zona del país. A continuación, se explican algunos de los rasgos generales del presente de indicativo en español, para pasar acto seguido al análisis de los usos de presente recogidos en el corpus de ejemplos. A la hora de analizar dichos usos, no se toman las formas de presente de manera aislada, sino que siempre se tiene en cuenta el contexto lingüístico donde aparecen. Por último, se ofrecen las principales conclusiones extraídas del estudio.

\section{La ciudad de Pereira y la variedad del español colombiano}

Como ya se ha señalado, la acción de la serie utilizada como objeto de estudio transcurre en la ciudad colombiana de Pereira. Dicha ciudad es la capital del departamento de Risaralda y principal ciudad del eje cafetero, ubicada en la región centro-occidental del país y cerca del valle del río Otún, en la Cordillera Central de los Andes colombianos.

La ciudad de Pereira tiene una población cercana a los 500.000 habitantes y es el quinto núcleo urbano más poblado de Colombia. Constituye una de las ciudades más importantes del país, por detrás de otras como Bogotá, Medellín, Cali o Barranquilla. Desde el punto de vista económico, político y social, se debe destacar la crisis en la que está inmersa la ciudad desde hace ya varios años, debido a la ruptura del pacto que regularizaba los precios del café y a las secuelas de un terremoto que tuvo lugar en el año 1999.

Desde el punto de vista de la dialectología, Colombia es uno de los países más estudiados de Hispanoamérica. Además de numerosos estudios sobre los dialectos del país, destaca el atlas lingüístico realizado por el Instituto Caro y Cuervo en 1981. El habla de Bogotá, que goza de un gran prestigio popular fuera y dentro del país, también aparece analizada en el proyecto de estudio coordinado de la norma lingüística culta de la ciudad de Bogotá.

Dentro del español hablado en Colombia, pueden distinguirse muchos dialectos. No obstante, como señala Lipski (2007) la única distinción que hacen todos los colombianos es la que opone a los costeños (habitantes de la costa) de los cachacos (habitantes de las tierras altas del interior). No obstante, si queremos definir con una mayor precisión la zona dialectal que aparece caracterizada en nuestro corpus de estudio, resulta útil seguir la clasificación dialectal propuesta por Montes (1996). Este autor considera conveniente, en primer lugar, dividir el conjunto del diasistema español en dos superdialectos: el continental interior o A y el costero insular o B. A su vez, ambos se dividirían en distintos dialectos. Dentro de dicha división dialectal, el ya mencionado departamento de Risaralda se encontraría dentro del dialecto andino occidental, perteneciente al superdialecto

\footnotetext{
2 Por cuestiones de espacio no pueden comentarse en profundidad todas las características fonéticas, gramaticales y léxicas de cada uno de los superdialectos y dialectos del español colombiano. Para un conocimiento más extenso resulta de gran interés la lectura del mencionado trabajo de Montes sobre Colombia dentro de la obra coordinada por Manuel Alvar: Manual de dialectología hispánica. El español de América (1996); así como otros trabajos de Montes donde trata de manera amplia el tema de la cuestión dialectal en Colombia, como es el caso del trabajo «El español de Colombia. Propuesta de Clasificación dialectal» (1982) aparecido en THESAURUS, tomo XXXVII, número 1.
} 
central andino, cuyos principales rasgos definitorios son: la conservación de la -s implosiva (no así en posición intervocálica), la distinción de las líquidas, el mantenimiento de la $-r$ final, entre otros. Asimismo este dialecto, podría subdividirse también en paisa o antioqueño (donde se incluye el departamento de Risaralda) y valluno.

\section{El uso del presente en español}

Si buscamos en el diccionario de la $\mathrm{RAE}^{3}$ el término presente nos encontramos con la siguiente acepción referida al ámbito gramatical: «tiempo que sirve para la acción o el estado de cosas simultáneos al momento en que se habla». No obstante, el presente no siempre expresa una estricta simultaneidad con el momento de habla, ya que como señala Alarcos:

Así el presente no significa la mera coincidencia de la noción verbal con el acto de habla, sino un segmento temporal en que ese acto está incluido. Por esta latitud de aplicación, puede usarse el presente para denotar hechos que en la realidad temporal están situados en zonas anteriores o posteriores al «ahora〉, o punto cronológico en que se manifiesta el yo que habla (Alarcos 1994: 156).

De la misma forma, la RAE (2010: 1709) afirma que «el presente expresa la coincidencia de la situación designada con el acto verbal en que se emite un enunciado», aunque matiza poco después dicha definición, al considerarla una interpretación poco común pues «el punto de la enunciación es, en sentido estricto, un instante, mientras que los hechos o los estados de cosas que se expresan con este tiempo verbal no tienen por qué ser momentáneos».

Los distintos matices de significado que puede expresar el presente lo convierte en la forma más utilizada del sistema verbal en el habla cotidiana de los hablantes de español, no solo entre la población adulta, sino también entre los niños, como señalaba ya Gili Gaya (1972) en sus estudios sobre el lenguaje infantil. En opinión de Sastre Ruano (1995: 29): «el ser el tiempo más neutro de todo el sistema verbal explica su multitud de usos y valores especiales, motivados por la situación y por los usos sintácticos y léxicos que lo acompaña». Todo esto ha propiciado que varios autores hayan propuesto distintas clasificaciones de los usos del presente (Fernández Ramírez 1986; Alarcos 1994; Marcos, Satorre y Viejo 1998).

Estas reflexiones gramaticales que nos ayudan a concebir una noción más amplia del presente, sin duda, serán de gran ayuda para comprender mejor los distintos usos de este tiempo verbal en los ejemplos de nuestro corpus de estudio.

\section{Análisis de los usos del presente en el serial colombiano}

En los materiales que constituyen nuestro corpus de estudio el presente de indicativo es el tiempo verbal que más aparece. Estos datos coinciden, por tanto, con los de otros trabajos sobre los usos verbales en las variedades americanas del español. Por ejemplo, en el estudio de Montes (2000) realizado a partir de una selección de algunas encuestas del proyecto El habla de la ciudad de Bogotá: materiales para su estudio llevado a cabo por el Instituto Caro y Cuervo, obtiene que el tiempo con una mayor frecuencia de uso es el

\footnotetext{
3 Definición localizada en el Diccionario de la Lengua Española -vigésima segunda edición- disponible en la dirección electrónica: http://www.rae.es/rae.html.
} 
presente de indicativo. Dicho autor (2000: 226) considera que esos resultados son bastante similares a los obtenidos en México y Chile.

Estos datos nos pueden llevar ya a una primera reflexión sobre los usos lingüísticos del serial analizado: su intento de reflejar fielmente el habla cotidiana y su deseo de conseguir una adecuada verosimilitud para los espectadores. El presente es uno de los tiempos más utilizados en la vida cotidiana y el serial recoge en sus escenas esa actualidad y dinamismo que caracterizan los pormenores de la existencia real, más aun tratándose de personajes como los de la serie, con un ritmo de vida bastante trepidante (huidas, persecuciones, amenazas, continuos planes, etc.).

El presente se utiliza para hablar de los hechos y rutinas habituales en el momento de la enunciación. Por eso, muchas veces aparece acompañado por adverbios u otras locuciones adverbiales que expresan esa temporalidad vinculada con el momento presente. Por ello, como defiende Matte Bon (2006) a la hora de estudiar un determinada forma verbal es fundamental examinar en profundidad sus relaciones con el resto de los elementos contextuales si queremos conocer sus significados concretos en cada contexto. Observemos los siguientes ejemplos del presente:

(1a)

- Entonces me tienes que dar la plata, además fue muy claro, la plata o la pelada, cualquiera de los dos pero ya.

- Sí, pero es que Jésica es la que tiene la plata y ella en este momentico no está.

$(1 b)$

¿Pero por qué me miente? ¿Por qué no me dice la verdad? Yo soy su amiga. Mi hijo, y esos tiros... Usted entró todo nervioso y últimamente anda en esos aparatos para arriba y para abajo.

En el ejemplo (1b) el cuantificador últimamente evidencia cómo el presente no se refiere en sentido estricto al momento de la enunciación, sino que puede referirse a situaciones referidas a un periodo temporal más extenso donde se encuentra incluido el momento de habla. Este uso como señala la RAE (2010: 1710) se puede denominar presente continuo, actual y presente ampliado o extendido.

Muchas veces el presente aparece junto con el adverbio ya para intensificar aún más ese valor de actualidad:

(2a)

- ¡Ay! Se está demorando como mucho la niña...

- Como ya no se le puede preguntar para dónde va.

$(2 b)$

- ¡Qué pena con usted, doña Ilda! Yo ya no salgo acá de su casa.

- Mi hijito, usted sabe que esta es su casa.

En los ejemplos anteriores, tanto las formas de presente ( $v a$, salgo) como la perífrasis poder + infinitivo conjugada en presente se refieren como el ejemplo (1b) a un periodo de tiempo más amplio donde se incluye el momento de la enunciación. De ahí, que se sobrentiendan elementos adverbiales del tipo últimamente.

Sin embargo, otras veces esa unión del presente con el adverbio ya sirve para intensificar el valor inminente de una acción que está a punto de suceder, con lo que el presente pasa a expresar un valor prospectivo que veremos en profundidad más adelante: 
(3a)

- Digo, pues, ¿qué pasó con la niña?

- Nada, doctor. Ya nos vamos, pues. Yo ya me voy.

$(3 b)$

¡Ay! Bueno, allá ella con sus locuras. ¿Saben qué? Yo me voy ya.

(3c)

- Mi hijo, ¿por qué no va y les trata de sacar algo?

- Listo, listo, ma, ya vengo, pues.

En otras ocasiones, la frecuencia expresada por la acción verbal es tan reiterada que el presente aparece acompañado por el adverbio siempre:

(4)

Estas no, Diablita. Estas están difíciles. Hasta les hemos mandado ofrecer hasta cien millones, camionados de ropa, joyas costosísimas, relojes con diamantes... todas las operaciones que quieras, las hemos mandado invitar a Europa, Japón... Y siempre dicen que no.

Este tipo de cuantificadores adverbiales como siempre dan lugar al llamado presente habitual o cíclico.

Resulta también habitual encontrar el presente dentro de frases hechas muy empleadas en el lenguaje coloquial, como por ejemplo:

(5)

Yo no sé, papá. Yo no tengo vela en el entierro.

Muchas veces el presente aparece dentro de oraciones con verbos que semánticamente expresan certeza y seguridad:

(6a)

- Entonces, ¿a quién estaban disparando?

- Bueno, pues yo que sé. Usted sabe que en este país a uno le disparan solo por verle caer.

$(6 b)$

- ¡Qué pena con usted, doña Ilda! Yo ya no salgo acá de su casa.

- Mi hijito, usted sabe que esta es su casa.

(6c)

- ¿En serio, Diabla?

- Que sí. Mariño sabe que yo soy una mujer muy seria.

$(6 \mathrm{~d})$

Catalina, yo sé que no le puedo dar todas las cosas que usted quiere. Pero nadie le puede dar el amor que yo le puedo dar a usted.

En varios de los ejemplos anteriores, observamos casos del llamado presente caracterizador o descriptivo para referirse a propiedades de las personas o las cosas, por ejemplo: $\mathrm{Mi}$ hijito, usted sabe que esta es su casa; Mariño sabe que yo soy una mujer muy seria. En el ejemplo Usted sabe que en este país a uno le disparan solo por verle caer con el presente disparan afirma un hecho de manera categórica, por lo que ese uso se relaciona con el llamado presente gnómico. Como señala la RAE (2010: 1713):

La posible verdad o falsedad de estos asertos es independiente del valor gramatical que corresponde en ellos al presente. De hecho, muchas creencias y juicios de valor se integran en este grupo, aun cuando solo representen el punto de vista del que los sostiene. 
A veces aparecen otros elementos lingüísticos (especialmente de tipo adverbial) para expresar el valor de «seguridad»:

(7a)

- Muchas gracias y la comida le quedó muy buena.

- Pues aquí hay por si quiere más.

- No, no, muchas gracias. Yo ya quedé bien, más bien le guardamos a Catalina que seguro llega con hambre.

(7b)

- ¿Qué hacemos con la plata? Toca volvérselo a Mariño, porque ese tipo así como es de amplio, puede ser muy peligroso.

- ¡Uy! Eso sí es cierto. ¡Pero qué pesados son con ese billetico!

Aprovechando ese valor de certeza, podemos emplear el presente para emitir hipótesis cuando se tiene un alto grado de seguridad, por ejemplo:

(8)

- ¿Y ahora qué?

- Pues ahora ya ves, a decir la verdad, ¿sabe?

- ¿Cómo le ocurre? Además nos mata.

En el ejemplo (8) sería también posible utilizar el condicional (mataría) o el futuro de indicativo (matará). Sin embargo, como analizaremos más adelante, el uso de ambos tiempos verbales ha sufrido un gran retroceso en la lengua hablada.

Es muy frecuente también que el presente de indicativo sea sustituido en muchas de las variedades del español americano por la perífrasis estar + gerundio. Esta construcción se ha generalizado tanto que a veces también sirve para expresar acciones puntuales:

(9)

- Precisamente le estoy trayendo aquí la plata mientras ella se alienta.

- Acá no aparece, Diabla. Tú sabes que yo soy serio, pero me gusta que sean serios conmigo también.

En el ejemplo siguiente, la perífrasis verbal expresa una situación que se halla en curso en el momento de la enunciación:

- ¿Y cómo así, hermano?

- Así como lo oye, hermano. Se antoja de Catalina, me dijo, la flaquita, que la necesita ya.

- ¡Ay! Ya sé lo que pasa. El patrón sabe lo de ayer, Caballo, ¿sí o qué? Y el patrón está desconfiando de usted.

En el ejemplo (10) la perífrasis aporta un carácter más enfático que la forma de presente (desconfía) que sería la habitual en ese contexto, pues el verbo desconfiar expresa una acción de cierta permanencia pero sin un principio y fin claros.

Otras veces el uso de la perífrasis y del presente actualiza tanto los hechos que pasan a adquirir un valor enfático de urgencia, muchas veces reforzado por otros elementos que también aportan dicho valor:

(11a)

Catalina acaba de cumplir su sueño. Aquí están los cinco millones de pesos que necesitaba.

Pero lo que yo necesito es que llegue ya, porque Mariño la está necesitando urgente. 
(11b)

- Oiga, Diablita, que vaya donde los patrones, que la están necesitando.

- ¿A mí? Y qué, ¿cuándo puedo ir?

El ejemplo (11a) resulta muy interesante porque aparecen combinadas la forma de presente y la perifrástica del verbo necesitar. En los usos peninsulares sería poco habitual emplear ahí la perífrasis, excepto si se quisiera aportar mucho énfasis a lo dicho; ya que no se trata de hechos progresivos sino más bien puntuales, no en sentido estricto, sino referidos a un intervalo indeterminado donde está incluido el momento de la enunciación.

En otras ocasiones, observamos también que la perífrasis se utiliza con acciones de cierta permanencia, como es el caso de los pensamientos, sentimientos u opiniones, que normalmente suelen expresarse con el presente:

- Le voy a comprar sus cositas, la voy a poner a vivir bien bueno y, si se porta como es, hasta su carrito le pongo. Pero, eso sí, está conmigo y con nadie más.

- Catalina: Pues claro, es que si voy a estar con usted, ipara qué voy a necesitar más!

- Listo, mi amor, ¿entonces así quedamos?

- Oiga, es que yo le estoy queriendo mucho.

- Hermano, el patrón me mandó traer la pelada que nos echamos anoche.

- Pues vámonos por ella.

- No, es que el patrón está pensando que la pelada está virgen todavía.

Normalmente, en el español peninsular no suele utilizarse el verbo querer en su forma perifrástica, ya que suele reflejar hechos de carácter bastante duradero para el hablante. Desde un punto de vista más pragmático, el empleo aquí de la perífrasis podría conducir a interpretaciones un poco maliciosas, ya que podríamos pensar que los sentimientos de la joven tienen un carácter meramente coyuntural, consecuencia directa de todos los bienes materiales prometidos por el hombre.

Aunque la mayoría de las veces las formas de presente son sustituidas por la perífrasis estar + gerundio, también podemos encontrar ejemplos en los que aparecen otras construcciones perifrásticas como variantes de presente:

(13a)

- ¿Y usted dónde va a sacar cinco millones, Caballo?

- ¡Y yo qué voy a saber, hermano!

- ¡Ay! Se está demorando como mucho la niña...

- Como ya no se le puede ni preguntar para dónde va. ¿Salgo a buscarla?

- Bueno, mi hijito. Ve y pregunte a las amigas si han de saber.

El ejemplo (13a) ofrece la expresión voy a saber muy habitual en el español coloquial en sustitución del presente. No obstante, la perífrasis haber de + infinitivo como equivalente al presente no suele utilizarse en las variedades peninsulares con este valor.

Otro de los usos más habituales en la lengua coloquial es el empleo del presente con un valor de futuro. Se trata del llamado presente prospectivo o presente pro futuro. Kany (1970: 189) ya señalaba el escaso uso del futuro sintético dentro del habla coloquial del español en América, sustituido por otras construcciones lingüísticas: «En numerosos países americanos se oye frecuentemente la observación de que el futuro va desapareciendo y que 
en la conversación apenas se usa, siendo reemplazado por el presente o por circunlocuciones varias». Por su parte, Alarcos (1994: 157) lo denomina presente de anticipación y explica que sirve «para denotar hechos todavía no ocurridos, pero cuyo cumplimiento se espera con seguridad en el porvenir». En este uso del presente normalmente suele aparecer dentro de la oración algún elemento que aporte un significado temporal.

(14a)

- Pero es que Jésica es la que tiene la plata y ella en este momentico no está, pero dígale que mañana le aparecemos con alguna de las dos cosas, ¿sí?

- Tú sabes que yo no me puedo volver con las manos vacías.

- Bueno, pues entonces mañana le devolvemos la plata a Mariño.

- Si queremos seguir viviendo es lo mejor.

- Es que necesitan que les consigas unas niñitas que les tienen loco. Puede ir cuando quiera.

Le están esperando.

- Listo, yo voy y hablo con ellos y luego le cuento. ¡Adiós!

En los ejemplos anteriores, observamos que el presente sirve para referirse a un futuro bastante cercano y, además, se muestra una gran convicción del hablante por llevar a cabo la acción verbal. De hecho, en los ejemplos (14a) y (14b) los hablantes son conscientes de la importancia que tiene cumplir con su misión de una forma adecuada si no quieren enfrentarse a serios problemas.

Otras veces, el sentido prospectivo aparece introducido por la conjunción temporal cuando:

(15)

La cagamos, hermano. Cuando el patrón se dé cuenta que nosotros nos lo adelantamos, nos quiebra, ¿qué hacemos?

El valor de futuro también se contagia a la perífrasis estar + gerundio como podemos observar en el siguiente ejemplo:

(16)

Es que le prometí cinco millones que es lo que le vale la operación de las tetas, hermano, y me está esperando allí en la Plaza Bolívar a las cuatro.

Otras veces, a ese sentido de futuridad también se añade un matiz de suposición, uno de los valores modales del futuro imperfecto de indicativo que se ha hecho muy habitual en el español actual. A veces, aparece algún elemento que refuerce ese valor o el contexto es lo suficientemente claro como para sobrentender ese significado:

Yo ya quedé bien, más bien le guardamos a Catalina que seguro llega con hambre.

- ¿Y no dices que la citaste a las cuatro de la tarde?

- Sí, pero con la ilusión que tiene por esa plata, ella me espera allí dos años.

En los ejemplos anteriores también se podría utilizar el futuro sintético (llegará, esperará) aprovechando su valor modal de probabilidad. 
Dentro de la conversación coloquial es frecuente que las formas de presente pasen a utilizarse como una marca fática vaciada de significado, de uso similar a las llamadas muletillas.

- ¿Y qué vamos a hacer, hermano?

- Yo no lo sé, pero hay que hacer algo ya.

- ¿Sabe qué? Cúbrame la espalda, hermano. Yo me voy para la plaza Bolívar a buscar a la niña.

- Lo que pasa es que las peladas de hoy en día no les ha terminado de sanar el ombligo y ya quieren tenerlo todo.

- ¡Ay! Bueno, allá ella con sus locuras. ¿Saben qué? Que yo me voy ya.

- ¿Y ahora qué?

- Pues ahora, ya ves, a decir la verdad, ¿sabe?

- ¿Cómo se le ocurre? Además nos mata.

En otras ocasiones, el presente se utiliza con un valor apelativo en segunda persona o la tercera en el caso de usted. Se trata del llamado presente de mandato o presente deóntico. Este uso constituye muchas veces un recurso atenuativo del valor de imperativo, especialmente si va dentro de un enunciado interrogativo. En estos casos, los pronombres personales aparecen antepuestos a la forma verbal:

Me hace el favor y me dice ya mismo qué es lo que está pasando.

Mi hijito, ¿me acompaña un momentico a la tienda a comprar unas cositas?

¿Usted me hace un favor? Cuando llegue le dice que se pase por mi casa.

Mi hijo, ¿por qué no va y les trata de sacar algo?

También puede utilizarse el presente en la primera persona del plural con un claro valor apelativo:

(20a)

- Hermano, el patrón me mandó traer la pelada que nos echamos anoche.

- Pues vámonos por ella.

- Pero usted dígale a Mariño que tranquilo, que yo se la llevo.

- ¿Ah, sí? Pues vamos por ella o la esperamos acá. Eso no son penas.

Por último, el presente también aparece en las oraciones condicionales. Su uso en la prótasis de las condicionales en ocasiones adquiere un valor prospectivo, pues en ese contexto no se admite el futuro en la lengua actual. En los ejemplos siguientes encontramos el presente en las dos cláusulas de las condicionales:

(21a)

¡Oiga! Pero si el patrón lo pregunta, ¿qué le digo, hermano? 
(21b)

- No, nada, la busqué en el centro y nada, no aparece por ningún lado.

- ¡Dios mío! ¡Mi niña!

- Pues mamacita, si quiere nosotros vamos y la buscamos otra vez.

- Mi mamá está preocupada.

- Si quiere yo le ayudo a buscar.

- Pues yo creo que ya no hay necesidad, porque allá viene.

Otras veces, también puede aparecer algún elemento adverbial que refuerce ese valor de futuridad del presente dentro de la oración condicional:

Bueno, si quiere yo mañana voy y las espero bien tempranito antes de que salgan de la casa.

Otras veces, aunque no aparezca la partícula condicional si las oraciones tienen un claro valor condicional:

- O sea que lo de los vidrios, ¿era mentira?

- No, no es mentira, lo que pasa es que estoy trabajando en otra cosa.

- Por Dios, Byron, ¿en qué?

- Es que yo le digo y usted me cantaletea.

- ¿Y no estará exagerando?

- ¿Exagerando? Como si vos no conociera a Mariño. Ese tipo se entera de que le desvirgamos a esa peladita y nos fusila.

En los ejemplos anteriores observamos que al omitirse la conjunción condicional explícita las dos formas verbales pasan a estar coordinadas por la conjunción copulativa $y$, la cual no podría mantenerse si se expresaran las oraciones como auténticas condicionales: Es que si yo le digo, usted me cantaletea; Si ese tipo se entera de que le desvirgamos a esa peladita, nos fusila.

\section{Conclusiones}

Las principales conclusiones que se extraen del presente estudio son las siguientes:

1. En el serial televisivo analizado observamos una gran presencia de las formas verbales de presente. Esta cuestión lingüística se relaciona con el deseo de conseguir una caracterización lingüística del serial que sea real y próxima a la vida cotidiana. Se consigue, además, un ritmo de gran dinamismo, en consonancia con las ajetreadas vidas de los personajes. Se puede hablar, por tanto, de verosimilitud en un doble plano: lingüístico y sociológico.

2. El presente tiene muchos valores distintos dependiendo del contexto lingüístico donde se inserte, de ahí la importancia de analizar sus relaciones con el resto de los elementos del enunciado. Los principales valores del presente registrados en el corpus de estudio son los siguientes:

2.1. Muchas veces aparece acompañado por elementos de naturaleza adverbial que refuerzan su relación temporal con el momento de la enunciación, no solo en sentido estricto (presente puntual) sino referido también a un periodo de tiempo más extenso 
donde se encuentra incluido el momento de habla (presente ampliado, actual o presente ampliado o extendido).

2.2. Si el presente aparece con el adverbio ya se refuerza aún más ese valor de actualidad o pasa a adquirir un valor de futuridad inmediata.

2.3. El presente se refiere también a acciones reiteradas en la vida de los hablantes, ayudado muchas veces por cuantificadores temporales (por ejemplo: siempre). Se trata del presente habitual o cíclico.

2.4. El presente aparece también utilizado en refranes u otras expresiones o giros populares.

2.5. El presente se encuentra muchas veces acompañado por verbos que semánticamente expresan la idea de «certeza» o «seguridad» (por ejemplo: saber) o por otros elementos gramaticales, especialmente, de tipo adverbial (seguramente) o adjetival (cierto). De esta situación se pueden derivar a menudo otros usos del presente, por ejemplo: el presente descriptivo o caracterizador, cuando se refiere a propiedades de personas o cosas, o el presente gnómico, cuando se afirma de manera categórica sobre hechos generales.

2.6. Muchas veces, el presente aparece sustituido por la perífrasis estar + gerundio. Ambas formas son equivalentes cuando se refieren a una situación que está en curso en el momento de habla. No obstante, debido a que el uso de esta construcción perifrástica se está extendiendo mucho en algunas zonas del continente americano, en el corpus analizado se registran ejemplos de uso de la perífrasis para referirse también a acciones de carácter puntual.

2.7. Tanto la perífrasis como el presente expresan a veces un valor enfático de urgencia, que puede estar reforzado por otros elementos lingüísticos, por ejemplo: ya, urgente, etc.

2.8. Algunas veces, la perífrasis estar + gerundio aparece expresando pensamientos o sentimientos de cierta permanencia en la vida de los hablantes, normalmente expresados con el presente. Desde un punto de vista pragmático, pueden interpretarse como actitudes caracterizadas por una cierta volubilidad.

2.9. El presente también puede aparecer sustituido por otras construcciones perifrásticas, como ir a + infinitivo o haber de +infinitivo. Este último uso es poco común en el habla cotidiana peninsular.

2.10. Es muy habitual a lo largo del serial el uso del llamado presente prospectivo o de futuro, frente al uso cada vez más reducido del futuro sintético en el español oral. Normalmente, en estos casos aparece dentro del enunciado algún elemento que aporta ese significado temporal de futuridad (mañana, luego, etc.).

2.11. Acompañado de la partícula temporal cuando el presente también adquiere a veces un valor prospectivo.

2.12. El valor de futuridad también puede aparecer embebido por un valor modal de suposición o probabilidad, un valor también muy habitual para el futuro sintético.

2.13. En ocasiones, en el español coloquial el presente se convierte en una marca fática vaciada de significado con el objetivo de mantener el ritmo conversacional.

2.14. El presente conjugado en segunda persona o en tercera en el caso del usted también presenta un valor apelativo, atenuando muchas veces el valor de imperativo, especialmente dentro de oraciones interrogativas. Se trata del presente de mandato 
o deóntico. Es muy frecuente también el uso del presente en primera persona del plural con un claro valor apelativo.

2.15. Por último, el presente aparece en oraciones condicionales. Cuando se encuentra en la prótasis condicional puede adquirir también, dependiendo del contexto, un valor prospectivo, a veces reforzado por la presencia de otros elementos temporales. Otras veces, aunque no aparezca explícitamente la conjunción si, el contexto de la oración la permite entender fácilmente como una condicional. En este caso, las dos cláusulas de la oración pasan a estar coordinadas por la conjunción copulativa $y$.

\section{Retos para el futuro}

En este trabajo, se han presentado de manera breve las conclusiones obtenidas de un primer estudio sobre el uso del presente en el serial colombiano Sin tetas no hay paraíso. Aunque los ejemplos utilizados contribuyen a ofrecer una primera imagen sobre el comportamiento de este tiempo verbal en los materiales empleados, se espera seguir trabajando en este tema con el fin de analizar los usos del presente en la totalidad de los capítulos que constituyen la serie. De esta manera, se espera poder obtener datos valiosos que permitan describir de manera bastante detallada las características lingüísticas de la variedad del español colombiano, así como sus diferencias y semejanzas con otras variedades dialectales del español de América y del español peninsular. Gracias a este tipo de estudios, podremos conocer mejor la riqueza de matices que definen nuestra lengua a ambos lados del Atlántico.

\section{Bibliografía}

Alarcos Llorach, Emilio (1994), Gramática de la lengua española, Madrid: Espasa.

Aleza Izquierdo, Milagros - Enguita Utrilla, J. María (2002), El español de América: aproximación sincrónica, Valencia: Tirant Lo Blanch.

Cisneros, Mireya (2003), «Breve aproximación al estudio del lenguaje en la telenovela colombiana», Revista Litterae 12, 124-142.

Cisneros, Mireya - Olave, Giohany - Rojas, Ilene (2009), «El lenguaje de la telenovela en la conducta lingüística de televidentes jóvenes: un estudio de caso», Perspectivas de la comunicación 2, 7-17.

FERnÁNDEZ de CASTRO, Félix (1999), Las perífrasis verbales en el español actual, Madrid: Gredos.

FERNÁNDEZ DE CASTRO, Félix (2007), «Relaciones entre flexión y perífrasis verbales», in: Camus Bergareche, Bruno (comp.), El tiempo y los eventos, Cuenca: Ediciones de la Universidad de Castilla - La Mancha, 77-94.

Fernández Ramírez, Salvador (1986), Gramática española, Madrid: Arco/Libros.

Frago Gracia, Juan Antonio - Franco Figueroa, Mariano (2001), El español de América, Cádiz: Servicio de Publicaciones Universidad de Cádiz.

GILI GAYA, Samuel (1972), Estudios de lenguaje infantil, Barcelona: Vox.

KANY, Charles (1970), Sintaxis hispanoamericana, Madrid: Gredos.

LAPESA, Rafael (1981), Historia de la lengua española, Madrid: Gredos.

LIPSKI, John (1996), El español de América, Madrid: Cátedra.

Lope Blanch, Juan Miguel (1972), Estudios sobre el español de México, México: Universidad Nacional Autónoma de México / Centro de Lingüística Hispánica. 
López Morales, Humberto (2010), La andadura del español por el mundo, Madrid: Taurus.

Marcos Marín, Francisco - Satorre Grau, F. Javier - Viejo Sánchez, María Luisa (1998), Gramática española, Madrid: Síntesis.

MartíneZ, José Antonio (1994), Propuesta de gramática funcional, Madrid: Istmo.

Matte Bon, Francisco (2006), «Maneras de hablar del futuro en español. Entre gramática y pragmática. Futuro, ir a + infinitivo y presente de indicativo: análisis, usos y valor profundo», RedELE 6 .

Montes Giraldo, José Joaquín (1982), «El español de Colombia. Propuesta de clasificación dialectal», Thesaurus, tomo XXXVII, núm. 1, 23-92.

Montes Giraldo, José Joaquín (1996), «Colombia», in: Alvar, Manuel (dir.), Manual de dialectología hispánica. El español de América, Barcelona: Ariel.

Montes Giraldo, José Joaquín (2000). Otros estudios sobre el español de Colombia, Santafé de Bogotá: Publicaciones del Instituto Caro y Cuervo.

Moreno de Alba, José G. (1988), El español en América, México: Fondo de Cultura Económica.

RAE (2010), Nueva Gramática de la lengua española. Sintaxis II, Madrid: Espasa.

Rojo, Guillermo - VeIGA, Alexandre (1999), «El tiempo verbal. Los tiempos simples», in: Bosque, Ignacio - Demonte, Violeta (eds.), Gramática descriptiva de la lengua española 2, Madrid: Espasa, 2682-2934.

Ruiz Mantilla, Jesús (2010), «El precio de la prostitución», El País Semanal, 1753, 56-66.

SAussure, Ferdinand de (1980), Curso de Lingüística General, Madrid: Akal.

SAstre RuAno, María Ángeles (1995), El indicativo, Salamanca: Ediciones Colegio de España.

Vigara TAuste, Ana María (1996), «Español coloquial: expresión del sentido por aproximación», in: Kotschi, Thomas - OesterReicher, Wulf - ZimMERMAnN, Klaus (eds.), El español hablado y la cultura oral en España e Hispanoamérica, Madrid: Vervuert Iberoamericana.

Zamora Munné, Juan C. - Guitart, Jorge M. (1988), Dialectología hispanoamericana, Teoría, descripción, historia, Salamanca: Ediciones de Colegio de España.

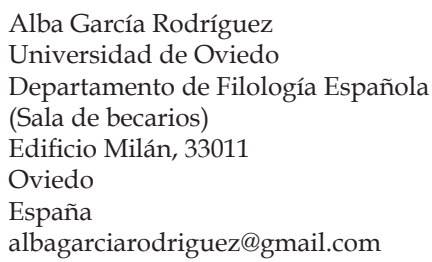

